\title{
Dialectic Approach in the Psychology
}

\section{Jose RP*}

Doctor in Psychoanalysis, Brazil

*Corresponding author: Jose RP, Doctor in Psychoanalysis, Brazil

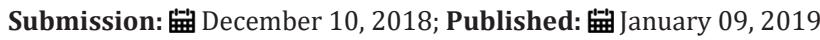

\section{Introduction}

The reality, from the inanimate matter until the society, and from unconscious psyche until conscience, it doesn't evolve in stochastic, chaotic course, but rather it is governed by an intrinsic determinism, given by the internal interaction of their components. This implies its self-movement, which runs in perennial ascent toward bigger complexity and adaptation. Nevertheless, this determinism is not strict, but rather leaves a margin of freedom through which influence the variables that impact on the evolutionary direction.

In this process takes place, in the climax of the biological interaction between the being with the natural environment, a qualitative jump without precedents. The synthesis, coalition, among internal and external conditions arrives to an end of complexity which generates a supra-structural and subjective system as solution, the psyche, and it continues an even more complex jump, the conscious psyche [1]. The interaction between elements across space and time implied the refraction of mutually transmitted influences, becoming more complex as living species emerged; more so in the human. This refractory process in the psycho-cerebral system consists on the filtration of information through its structural steps where it is analyzed, interpreted and processed for answer, from a preliminary, no-conscious stage, until understanding and answer fully conscious.

Starting from the refraction of the information, and as resultant, takes place a process of readjustment, managed to the harmonic integration in the neural circuits. Consequently, the individual control is conscious, but regulated underlying by the structures of the psycho-cerebral system. In other words, the answer takes place as reaction to the circumstances, but it is filtered, gauged and adjusted, through the structural regulation no-conscious. Somebody, for example, it is sensitized or saddened before an event given without apparent explanation, but in fact the fact is linked to a motivation, passion, or frustration happened previously, without being known the relationship cause-effect.

The fundamental approach in this refraction process is the consistency the grade of harmony, and therefore acceptance of the information. If it is appropriate is integrated expedite to the structural system, in fact is neural integration, but if the information is incongruous its integration is rough, and it is required the intervention of mechanisms of readjustment for the reestablishment of the balance. In these paper is defined the psyche like the subjective system that it emerges of the neural system, and to which incorporates and re-elaborates the reality; material and immaterial. As system, finally possesses functioning and structuring, and both are generated mutually. The functions create the structures, and these once created, they pass to regulate the functions again.

But this interaction and synthesis between psyche and body have not always been taken sufficiently into account. Philosophical currents, Cartesians [2], Pragmatism [3], Positivism [4], and their later influence in the psychological theory of the Behaviorism [5] have ignored the Hippocratic precept of the integration of mindbody. To it is added it that the connection mind-body has been object of philosophical polemic from the beginnings of the civilization, reaching to the scientific field through the time.

The relationship mind-body has implied a discussion that has been inserted in the center of the opposition among the philosophical paradigm of mechanic trend and its opposed one, the dialectical. Each one establishes an explanatory mark of the movement and change of the reality, including the objective one and the subjective one, but in a different way. The philosophy of mechanic trend contemplates the external influence as generator of the movement but obviating the intrinsic forces. On the contrary, the paradigm dialectical taking in bill the paper of the external forces but are refracted through the internal conditions; that is to say, the modification and influence of a body on another is according to the essence and identity of each one.

The focus mechanic in the study of the human becomes significant starting from the concept man-machine, of Renato Discard 1596-1650. This Cartesian dualism, which distinguishes the Thinking Substance, the mind, and the Extensive Substance, the body, radicalizes the separation between both. Cooperating to this conception appears Isaac Newton's physics later 1643-1727. Starting from the Cartesian philosophy, when lapsing of the time, were inspired philosophical other currents as the Positivism and Pragmatism. The Positivism begins with August Comte 17981857 whose fundamental idea consisted in contemplate as valid only the objectively observable and appraisable. Consequently, it is considered the scientific experimentation as the only one in route to the truth. This form of thinking predominated long time in the philosophical thought, and in wide sense it is a rejection to the Metaphysics, developed by Aristotle in the antiquity and which 
contemplates the man's non-appraisable aspects. The Pragmatism originates it William James [6] who considers of alone value the useful thing.

These currents lead to the Empiricism, which emphasizes the value of the scientific mensuration. This way the road opens up toward the Behaviorism, with John's figures as Broadus Watson 1908-1921 and Frederic Skinner 1904-1990. However, the Positivism derives in the Post-positivism. This new current considers insufficient the empiric evidence to arrive to the scientific truth due to the multiplicity of variables that you/they intervene in a phenomenon, that which opens error possibility despite the objectivity. To the Post-positivism follow the Constructivism, derivative from the theory of Jean's Piaget, this establishes that everyone builds his reality. This current contemplates the possibility that stereotyped beliefs, archetypal, given by the tradition or influenced by the massive communication, makes interference to the critical thought; in fact, it also reaches to the scientific field.

Another philosophical current related to the man's psychological focus, and that it reaches the XX century, it is Perspectivism. This conception, with edge of Post-positivism, has its premises in Gottfried Wilhelm Leibniz 1646-1716 who sustains that the perception and thinking take place from the perspective peculiar of the individual. Consequently, each one "possesses their reality", to the margin of existing an absolute one. On the other hand, the opposed current to the mechanic trend, the dialectical one, also originated in the antiquity, but not like is conceived in the current times. Flashes of their conception are observed in the preSocratic thinkers who had the nature like their observation object. Heraclitus considered the perpetual change when making the statement that nobody takes a bath twice in the same river, things remain changing and change staying, and at the same time, ones push to others.

For Democritus all existence was composed by indivisible atoms, that which supposed the intrinsic unit of the matter According to Hippocrates, mentioned by Plato in Dialogues, "The nature of the body can only is understood as a unity; and this it is the great error of our days in the treatment of the human body that the doctors separate the soul of the body." Although in these positions the dialectical interpretation, as is known at the present time, it was far from the method fully scientific, a conception is observed more teleological that mechanic the reality in its self-movement. The Dialectical is exposed for the first time by Zeno of Elea (490430 to. C.) in his book School, and it was referred to the polemic as conversation method. On that base, with Socrates, Protagoras and the sophists, an important turn takes place in the vision on the human being, acquiring the dialectical bigger participation like thought method.

Plato develops his conception of the Socratic method in his book Dialogues. There he considered thesis the initial argument, its opposed one, the antithesis, and the resulting truth of this opposition, the synthesis. The Socratic Method approached the polemic by means of questions and answers, driving to the rebuttal of the discussed argument; in this way is possible arrive to the truth. But at the same time this method hid inside itself the contradiction like it is known in this moment. Aristotle on the other hand, in their search of the truth he/she comes closer to the dialectical that which exposes in his book Metaphysics. In the old East it was also meditated on the bond between the soul and the body with dialectical shades, although inside a context different to the Westerner. For example, in the Buddhism it is contemplated as the being is created and destroyed continually. The Taoism observes the Ying/Yang like opposed forces, and at the same time are inside the Tao. In the Hindu thought the diversity and contradictory events are manifestations of the unit.

The decadence of the splendor of the Old Age brought I get the feudal forms of the distribution of lands, moving to the rural field the epicenter of life and production. On one hand the servants and peasants were, ingrained and fused to the earth, while the gentlemen remained locked in castles and walled houses, and for other one, the rigid monastic norms, exercised strong control in the mentality of the masses of that time. These conditions reduced the conscience of individuality.

However, advanced the European Middle Ages arises the query again on the human being, granting to the individual bigger conscience of itself. Next to it, with the effect of the Reformation in the ecclesiastical world Europe returns again to the humanism and individualism, leaving behind the symbiosis characteristic of the feudal life. As it lapsed the time, in the later centuries, other outstanding thinkers arose; among them, Emmanuel Kant 1724-1804 and Georg Wilhelm Friedrich Hegel 1770-1831. Kant constituted a landmark in the transition toward a different focus in the conception on the man's psyche. In their work Rehearsal of introducing the concept of the negative magnitudes in the philosophy, published in 1763, it considers that: "the soul understands the whole universe with its representative abilities, although it is clear, is only a particle of those representations."

Later, Kant exposes in Critic of the pure reason, published in 1781, and referring to the conceptualization: It is "the synthesis in general, as we will soon see, the simple work of the imagination, a blind function although indispensable of the soul, without which would not have knowledge of anything, function of the one which rarely have conscience." With Hegel the old one dialectical, of a rhetorical and argumentative character, finally it gives step to a method logical; besides, is premises of the current theory of the system. His most important book was Phenomenology of the spirit, published in 1808, and its cardinal conception resides in that the development is caused by multifaceted matrix of internal and external contradictions to the being, and not for exclusive pressure of external forces. The external causes act and they are refracted through the internal conditions.

For Hegel the reality is the constant interaction of opposed elements, that which takes place through the continuous contradiction; in that way are inter-penetrated itself. This philosopher considers that everything is contradictory, and it is the root of the movement, that is to say, self-movement. For him, only what contains contradiction moves. Hegel constitutes continuation 
of the thought of Johann Gottlieb Fichte 1762-1814 who previously focused the conception of contradictory unit. To Fichte the thesis is to "be in itself", the antithesis is its negation, where being "to be in itself" it comes out of itself and becomes opposed, denies it. This way, thesis and antithesis are in contact, union, but given their differences take place the contradiction between them. In this contradiction they are influenced mutually, the identity and presence of one, by itself, is action on the other one. That interaction leads to the mutual integration and rise the third consequently synthesized. For Hegel the synthesis was truer than the thesis and the antithesis meetings.

In other words, the alive or not alive beings, objectives or subjective, materials or spiritual, they possess their own identity, their essential quality; each being is only, exclusive and different. But as this identity trend to the immanence, the contact among them supposes the spontaneous imposition from one to the other. In that way the inter-penetration takes place between both contrary, appearing the third as a result synthesized. This new being, which constitutes the synthesis of the contrary ones that engendered it, contains the qualities, the identity, of both. Also, once arisen enters in new external contradiction, repeating the contradictory process until the infinite. Consequently, the created synthesis bears characteristic of the old, it is new but at the same time it is old; in that coalition of contrary each being is transforms in opposed, but it is the same thing.

At the same time, if in the contradictory unit each contrary imposes, and it transmits their own identity to the other one, then in each one a new contradiction is established internally, among the received identity from the contrary one and the own. In each contradiction that takes place, each one of the contrary ones implies new contradiction inside itself. In consequence, each contradiction, in fact, it is external and internal at the same time. The prevalence of one of the contrary ones on another is determined by the grade of internal harmony of each one in the relationship thesis-antithesis. That is to say, the coherence and strength of one or another is who determines the predominant characteristics of the synthesis. To mention a simple example, the aggression to a cohesive family implies that this he/she unites monolithically, but those sunk in discords and internal conflicts spread to transfer the external contradiction toward inside them, with the rising family disintegration.

The waves collide against the rocks and it converts in sand, and this once arisen, influence on the water again. The animal species that is not capable to subsist in each atmosphere, it is defenseless until disappearing, like it has happened during millions of years. Other, for example some insects, absorb characteristic of the environment, useful for the camouflage and defensive answer. Some reptiles mimicked with the environment, and they even assume its colors, allowing to them subsist. In developed species it is observed how the behavior is conditioned to facilitate better defense and feeding; for example, in the experiments of Wolfgang $\mathrm{K}$ [7], the simian manipulates one and another time with bars until finding the solution to obtain the food. Finally, there are species, as the shark, which are fossil alive because they have remained unalterable in the time due to their capacity of subsistence.

\section{References}

1. Koehler B (2011) Psychoanalysis and neuroscience in dialogue: commentary on paper by Arnold H Modell. Psychoanalytic Dialogues 21: 303-319.

2. Farnell B, Varela CR (2008) The second somatic revolution. Journal for the Theory of Social Behaviour 38(3): 0021-8308.

3. Friedrichs J, Kratochwil F (2009) On acting and knowing: how pragmatism can advance international relations research and methodology. International Organization 63(4): 701-731.

4. Cruickshank J (2012) Positioning positivism, critical realism and social constructionism in the health sciences: a philosophical orientation. Nurs Inq 19(1): 71-82.

5. Watrin JP, Darwich R (2012) On behaviorism in the cognitive revolution: myth and reactions. Review of General Psychology 16(3): 269-282.

6. James W (1981) Pragmatism. Indianapolis: Hackett Publishing Company, USA

7. Kohler W (1925) Intelligence in apes. The Journal of Genetic Psychology 32(4): 674-690.
Creative Commons Attribution 4.0 International License

For possible submissions Click Here

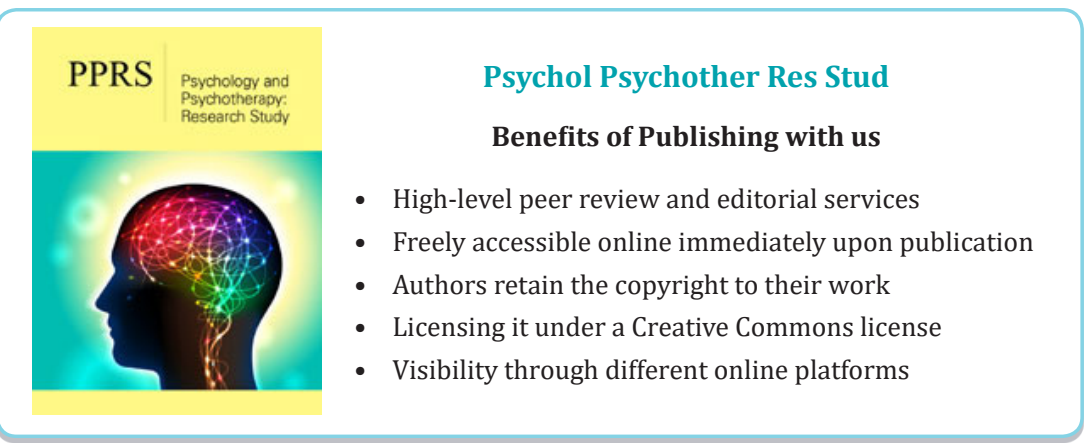

